\title{
MACROECONOMIC PERSPECTIVE ON CONSTRUCTING FINANCIAL VULNERABILITY INDICATOR IN CHINA
}

\author{
Tai-Hock KUEK ${ }^{1}$, Chin-Hong PUAH ${ }^{1 *}$, M. Affendy ARIP ${ }^{1}$, \\ Muzafar Shah HABIBULLAH ${ }^{2}$ \\ ${ }^{1}$ Faculty of Economics and Business, Universiti Malaysia Sarawak, Kota Samarahan, \\ Sarawak, Malaysia \\ ${ }^{2}$ Institute of Agricultural and Food Policy Studies, Faculty of Economics and Management, \\ Universiti Putra Malaysia, Serdang, Selangor, Malaysia
}

Received 08 July 2019; accepted 31 March 2020

\begin{abstract}
This paper attempts to develop a financial vulnerability indicator for China as a barometer for the state of financial vulnerability in the Chinese financial market, possibly for real-time application. Twelve variables from different sectors are utilised to extract a common vulnerability component using a dynamic approximate factor model. Through the implementation of a Markovswitching Bayesian vector autoregression (MSBVAR) model, the empirical results indicate that a high-vulnerability episode is associated with substantially lower economic activity, but a low-vulnerability episode does not incur substantial changes in economic activity. Notably, the constructed indicator can serve as a real-time early warning system to signify vulnerabilities in the Chinese financial market.
\end{abstract}

Keywords: financial vulnerability indicator, financial crises, early warning system, dynamic factor model, Markov-switching model, China.

JEL Classification: C11, E17, G01, G17.

\section{Introduction}

Since 1995, economic development in China has been blessed with a remarkable acceleration of double-digit growth; except for the slowdown in 2014 due to the global economic meltdown, the average has been annual growth of 16 percent. Because of its evolution into an open economy, China was only marginally affected by the Asian financial crisis in 1997, the United States (US) dotcom bubble burst in 2001 and the hard hit from the subprime mortgage crisis in 2008. The sustainability of such rapid growth before the crisis was obstructed due to capital flight and the sudden collapse of external markets followed by the threat of deflationary pressure towards the end of 2008 (Yu, 2010).

*Corresponding author. E-mail: chpuah@unimas.my

Copyright (c) 2020 The Author(s). Published by Vilnius Gediminas Technical University

This is an Open Access article distributed under the terms of the Creative Commons Attribution License (http://creativecommons. org/licenses/by/4.0/), which permits unrestricted use, distribution, and reproduction in any medium, provided the original author and source are credited. 
The economic recovery from the global financial crisis was hastened following the expansionary fiscal and monetary policy responses by the Chinese government coupled with a shift to property investment as an attractive destination for the high-domestic-saving nation of China. The removal of credit restrictions and relaxed property lending led to a sudden upsurge in real estate investment, averaging approximately a 39 percent growth rate in real estate investment value from 2007 to 2014. As a result of demand-led property price hikes, a property bubble began to inflate in some major cities, accompanied by a worsening in average credit quality, which led to fears of vulnerability to an asset price bubble, as Japan experienced in the 1980s (International Monetary Fund [IMF], 2010). After years of property booming, the low commodity demand from China triggered the global economic meltdown in 2013 through stock market and commodity bubbles. Nevertheless, the Chinese economy sailed through the meltdown with its strong domestic consumption, particularly in real estate investment.

China's economic growth dependence on exports and investment, particularly in the property market, has elevated its financial vulnerabilities from possible external shocks like the global financial crisis and global economic meltdown. Both China's President Hu Jintao and its Premier Wen Jiabao also raised concerns about the unsustainability of China's rapid economic growth due to the high contribution of exports and investment to the gross domestic product (GDP) but with a low share of domestic consumption. To tackle such phenomena, the government of China is pushing an effort to shift to consumption-driven economic growth in rebalancing the country's economy. The transition from debt-financed investment to consumption would ensure sustainable economic growth in an environment of much-reduced vulnerability (IMF, 2018).

In the midst of financial reform and transition in policy focus, China faces potential vulnerabilities common to an evolving financial system. Despite the implementation of cooling measures, property prices in China have remained unsustainable while excessive credit expansion still exists, hitting an all-time high credit-to-GDP ratio of 256.3 percent in 2017 (IMF, 2018). A report by the International Monetary Fund (IMF, 2016) served as a warning regarding China's high credit expansion leading to amplified economic and financial risks. Lying beneath the credit expansion due to financial integration, the proliferation of shadow credit products, reflected by the volume-to-GDP ratio hitting 58 percent in 2015, may also represent substantial vulnerabilities to the financial system as half of the products contain significantly elevated default risk and potentially less manageable spill-over effects (IMF, 2016). On top of that, challenges and vulnerabilities remain a threat to financial and economic sustainability in China, posed by the increasing imbalances stemming from the current economic growth path.

Pertaining to these issues, Cecchetti, Mohanty and Zampolli (2011) claimed that despite the huge contribution of debt to economic development, debt could also bring about an economic slump. Historically, credit crunches and asset price busts represent more severe downturns, typically about 10 times and 15 times, respectively, as compared to other downturns (Claessens \& Kose, 2013). Credit crunches and asset price busts would affect the real economy through further credit impairments and a weak outlook on large price dislocations by financial institutions, bringing about a more severe contraction in real economic activity. 
To preserve sustainable economic growth, the construction of a financial vulnerability indicator (FVI) that serves as an early warning system is essential in monitoring vulnerability of the financial system and economy as a whole. The constructed leading indicator, acting as a forecasting instrument, would have the ability to predict fluctuations in the Chinese financial market and monitor vulnerability-posing fundamental deviations that could stunt economic growth. To the best of the authors' understanding, the financial market of China has yet to possess a leading indicator to foretell financial vulnerabilities. Therefore, the present study attempts to investigate the fluctuations in the Chinese financial market by constructing a financial vulnerability indicator.

The remaining structure of this paper is divided into four sections. Section 1 summarizes the review of past studies on early warning mechanisms. Section 2 presents the econometric methodology employed for indicator construction and estimation on the impacts of financial vulnerability while Section 3 discusses the empirical findings of the study. The discussion of this paper is completed with the Conclusion section.

\section{Literature review}

Research interest in early warning indicators has renewed since the global financial crisis in 2008-2009; the indicators aim to assist in financial crisis forecasting by monitoring key variables. Nevertheless, study of early warning systems dates back to Kaminsky and Reinhart (1996, 1999). Using the signals approach, they assessed the vulnerability of an economy and developed an early warning system for currency and banking crises. Later, Bruggemann and Linne (2002) extended the signals approach by employing a composite indicator for the Central and Eastern European transition countries and more techniques for indicator construction have emerged thereafter. By compiling the variables into a single indicator, the researchers showed that overvaluation of the exchange rate, weakening of exports and dwindling currency reserves were among the variables that possessed good predictive power in the assessment of crisis vulnerabilities.

Prior to the global financial crisis, Illing and Liu (2006) combined survey and econometric methodology in developing an index of financial stress for the financial system in Canada and discovered the usefulness of the developed index in measuring financial stress. Moreover, Bussiere and Fratzscher (2006) proposed the utilisation of a multinomial logit model for crisis forecasting where economic fundamentals react differently between tranquil and crisis periods. With the substantial spill-over effect of financial vulnerability on economic activity experienced in previous crises, Cardarelli et al. (2011), Cevik et al. (2013a, 2013b) and van Roye (2014) constructed a financial stress index for different countries and regions. They showed that financial stress has a significant impact on economic activity. In particular, Cevik et al. (2013a) implemented principal component analysis while van Roye (2014) used a dynamic approximate factor model in developing their respective financial stress indexes. Using the multivariate generalized autoregressive conditional heteroskedasticity (GARCH) model, Louzis and Vouldis (2012) proposed a financial system stress index for Greece and noted that precise prediction regarding the nature of systematic stress is crucial in serving as policy guidance. 
In addition, Aboura and van Roye (2017) proposed a financial stress index for the French financial market using a dynamic approximate factor model consisting of $17 \mathrm{fi}$ nancial variables. Using a Markov-switching Bayesian vector autoregression and a wavelet procedure, respectively, Aboura and van Roye (2017) and Ferrer et al. (2018) reported that the impact of financial stress on the real economy is principally substantial during episodes of major financial turmoil. Similar to the approach of Aboura and van Roye (2017), $\mathrm{Li}$ and Xiao (2016) utilized data of quarterly basis from various segments of the Canadian financial market in constructing an early warning model to predict financial stress episodes. Based on the empirical outcome, the authors discovered that credit-regime-switching approach produce higher predictive power as compared to the benchmark models based on a linear regression and signals approach. While most early warning studies have focused on developed economies, Tng and Kwek (2015) and Cevik et al. (2016) respectively, focused on the Association of Southeast Asian Nations (ASEAN)-5 and emerging Asian economies to study the impact of financial stress on the economy, while Puah et al. (2017) and Tanaka et al. (2018) analysed a country's financial vulnerability by aggregating indicators across the whole economy and the banking sector through implementation of the different approaches. Similar to the approach of Aboura and van Roye (2017) and Li and Xiao (2016), Suidarma et al. (2017) implemented Markov switching modelling in developing an early warning system for the Indonesian financial system. The authors noticed the early signs of vulnerability through growth of credit to GDP, spread of interest rate, fiscal deficit, current account, exchange rate and differentials in interest rate. On the other hand, Stona et al. (2018) stressed the importance of appropriate policies during adverse conditions through their study on the case of Brazil.

With the intensifying importance in monitoring the health of the financial system, Kuek et al. (2019) and Arip et al. (2019) developed the financial vulnerability indicator for the case of Malaysia using different approaches. The authors noted that early warning mechanisms are useful in forecasting financial vulnerabilities by acting as a leading indicator. Kuek et al. (2019) discovered that the causes of crises are multidimensional where internal and external macroeconomic conditions are critical and significant in defining a country's vulnerability. On the other hand, Monin (2019) revealed that a financial stress index (OFR FSI), developed by the Office of Financial Research, worked well in tracing systemic financial stress. The author added that the increment in financial stress foretells a slowdown in an economy. Sahoo (2020) utilized high frequency data from money market, bond market, equity market, foreign exchange market, and the banking sector in constructing a financial stress index for the Indian economy. Similar to the finding from Monin (2019), Sahoo (2020) found out that financial stress ensues in slowdown in economic growth and added that higher economic growth for a certain period of time gives rise in financial stress. Similarly, Ishrakieh et al. (2020) implemented three market segments data from the Lebanese financial system in developing a financial stress index as a monitoring tool to maintain financial and economic stability in Lebanon. 


\section{Methodology}

Financial vulnerability is regarded as circumstances of the greater chances in producing stress to the financial system in the future (Pasricha et al., 2013). The exposure of certain risks to the financial system would define the degree of financial vulnerability. Due to imbalances in the financial system, financial vulnerability could expose the financial system with the risk of unforeseen corrections and even limiting its capacity to withstand other type of shocks. Identification of financial vulnerability can be done through the detection of imbalances in the financial system to act as a sign of future financial stress episodes. A severe occurrence of financial stress is regarded as a financial crisis. In general, a financial crisis has a strong linkage with some occurrences, namely, a substantial change in the credit volume and asset prices, severe disruptions to the financial system in terms of intermediation and financing, serious issues on balance sheets and government intervention (Claessens \& Kose, 2013). These occurrences often result in poor efficiency in the financial system, leading to a severe waning in economic activity (Mishkin, 1991).

With the existence of financial globalisation, the contemporary financial market is no longer evolving around the fundamental factors. Typically, financial crises are multidimensional events where a single indicator can hardly describe the whole stressful episodes, needless to say, it is challenging to source for the meticulous roots of the crises happening. Though fundamental aspects, such as macroeconomic imbalances, internal or external shocks, are closely monitored by the relevant authorities, financial crises sometimes occur due to irrational factors (Claessens \& Kose, 2013). The factors leading to financial turmoil may entail of an abrupt bank run, contagion and spill-over effects among financial markets, limits to arbitrage during a stressful period, the occurrence of asset busts, credit crunches, fire sales, and other related characteristics. Nevertheless, financial crises are frequently headed with booms in assets and credit which ultimately tailed into busts (Thakor, 2015).

Generally, financial vulnerability is not straightforward to measure while changes in a single variable can seldom be used to explain the whole situation. However, construction of one single indicator can serve as a proxy for financial vulnerability. The constructed single indicator can reflect the state of financial vulnerability, serving as a barometer for the financial system. A wide range of variables from the real sector, financial sector, external sector and capital account is considered for the indicator construction as financial vulnerabilities may have multiple dimensions. For indicator construction, the dynamic approximate factor model implemented in this paper follows the application of Banbura and Modugno (2014) and van Roye (2014), combined with the expectations maximization algorithm, while the Markov-switching model utilised is similar to the methodology Sims et al. (2008) employed to analyse the impact of financial stress on economic activity.

\subsection{Dynamic approximate factor model}

The dynamic approximate factor model can be presented in state space form. The measurement equation relates the observed data to the state vector of the latent factor, $f_{t}$. Following the application of van Roye (2014), a single factor is implemented for the estimation because inclusion of more factors does not meaningfully alter the empirical findings. 


$$
y_{t}=\Lambda f_{t}+e_{t}, \text { where } e_{t} \sim \operatorname{iid} N(0, C),
$$

where $y_{t}$ is a vector of stationarity and standardized endogenous variables of financial, property and macroeconomic data, $f_{t}$ is a single common latent factor and $\Lambda$ is an $n \times 1$ vector of the factor loadings of each variable. The factor loadings reflect the degree to which each time series is influenced by the common factor. The (FVI) is given by $F V I_{t}=\Lambda f_{t}$. The notation of $e_{t}$ is an $n \times 1$ vector representing the idiosyncratic component, which is allowed to be in low correlation in terms of series and cross-section at all leads and lags to prevent overrestriction. The following transition equation denotes the dynamics of the latent factor $f_{t}$,

$$
f_{t}=A f_{t-1}+\epsilon_{t} \text {, where } \epsilon_{t} \sim \operatorname{iid} N(0, D)
$$

where $A$ is the autoregressive coefficients matrix, gauging development of the latent factor $f_{t}$ in an autoregressive model over time.

The estimation of the dynamic approximate model in this paper follows the work of Banbura and Modugno (2014) and van Roye (2014) through combination of the maximumlikelihood approach and the expectation maximization algorithm initially suggested by Dempster et al. (1977). Prior to that, the time series are de-meaned and standardised. The dynamic model discussed allows for an efficient treatment of ragged edges, mixed-frequency data and a random pattern of missing data.

The advantage of implementing the approach based on the expectation maximization algorithm allows for estimation of an unbalanced panel. The iterative algorithm offers an efficient estimation and maximizes likelihood with incomplete or latent data. Based on the expectation maximization algorithm, the estimation involves two steps. The first step of estimation step encompasses estimation of missing data by means of existing parameter estimates and the conditional expectation. The second step of maximization step comprises maximization of the likelihood with the assumption that the data are identified. At each iterative step, the algorithm guarantees convergence with its increasing likelihood.

The first step of estimation step initiates with the computation of the expectation of the log-likelihood conditional on the data by using the estimates from the prior iteration $\theta(I)$,

$$
L(\theta, \theta(i))=E_{\theta(i)}\left[l\left(Y, F ; \theta \mid \varphi_{T}\right] .\right.
$$

The estimation of the parameters is repeated through a log-likelihood maximization with respect to $\theta$ :

$$
\theta(i+1)=\arg E_{\theta(i)}\left[l\left(Y, F ; \theta \mid \varphi_{T}\right] .\right.
$$

The estimation is carried out based on the work of Banbura and Modugno (2014). The parameter set comprises of four components whereby $\theta=\{\Lambda, A, C, D\}$. Maximizing Equation (3) follows through with the iteration processes of the factor loading matrix $\Lambda$ as well as the matrix $A$ of coefficient of the autoregressive in the dynamic factor of Equation (2):

$$
\Lambda(i+1)=\left[\sum_{t=1}^{T} E_{\theta(i)}\left[y_{t} f_{t}^{\prime} \mid \varphi_{T}\right]\right]\left[\sum_{t=1}^{T} E_{\theta(i)}\left[f_{t} f_{t}^{\prime} \mid \varphi_{T}\right]\right]^{-1}
$$

and 


$$
A(i+1)=\left[\sum_{t=1}^{T} E_{\theta(i)}\left[y_{t} f_{t}^{\prime} \mid \varphi_{T}\right]\right]\left[\sum_{t=1}^{T} E_{\theta(i)}\left[f_{t} f_{t}^{\prime} \mid \varphi_{T}\right]\right]^{-1}
$$

which is alike to an estimation of an ordinary least squares of the log-likelihood for data sets without missing values. The only dissimilarity for estimation of data sets with missing values is the introduction of expectation terms. The computation of the iteration processes for the covariance matrices follows:

$$
C(i+1)=\operatorname{diag}\left[1 / T\left(\sum_{t=1}^{T} E_{\theta(i)}\left[y_{t} y_{t}^{\prime} \mid \varphi_{T}\right]-\Lambda(i+1) \sum_{t=1}^{T} E_{\theta(i)}\left[f_{t} y_{t}^{\prime} \mid \varphi_{T}\right]\right)\right]
$$

and

$$
D(i+1)=1 / T\left(\sum_{t=1}^{T} E_{\theta(i)}\left[f_{t} f_{t}^{\prime} \mid \varphi_{T}\right]-A(i+1) \sum_{t=1}^{T} E_{\theta(i)}\left[f_{t-1} f_{t}^{\prime} \mid \varphi_{T}\right]\right)
$$

Subsequently, the data is undergone through the Kalman smoother in order to compute the moments of the unobservable factors.

With the incomplete sets of data sample, a diagonal selection matrix $W$ has to be implemented to further develop the factor loading matrix from Equation (4):

$$
\operatorname{vec}(\Lambda(i+1))=\left[\sum_{t=1}^{T} E_{\theta(i)}\left[f_{t} f_{t}^{\prime} \mid \varphi_{T}\right] \Lambda W_{t}\right]^{-1} \operatorname{vec}\left[\sum_{t=1}^{T} E_{\theta(i)}\left[W_{t} y_{t} E_{\theta(i)}\left[f_{t}^{\prime} \mid \varphi_{T}\right]\right]\right]
$$

Likewise, the evolvement of Equation (7) is as follows:

$$
\begin{aligned}
& D(i+1)=\operatorname{diag}\left[1 / T\left(\sum_{t=1}^{T} W_{t} y_{t} y_{t}^{\prime} W_{t}^{\prime}-W_{t} y_{t} E_{\theta(i)}\left[f_{t}^{\prime} \mid \varphi_{T}\right] \Lambda(i+1)^{\prime} W_{t}-\right.\right. \\
& W_{t} \Lambda(i+1) E_{\theta(i)}\left[f_{t} \mid \varphi_{T}\right] y_{t}^{\prime} W_{t}+W_{t} \Lambda_{t+1} E_{\theta(i)}\left[f_{t} f_{t}^{\prime} \mid \varphi_{T}\right] \Lambda(i+1)^{\prime} W_{t}+ \\
& \left.\left.\left(I-W_{t}\right) C(i+1)\left(I-W_{t}\right)\right)\right] .
\end{aligned}
$$

The period under study for the indicator constructed using dynamic approximate factor model (DAFM) spanned from 1998M01 through 2018M07. The GDP data, stated on a quarterly basis, are divided by the consumer price index (CPI) to obtain the value in real terms. Application of the Chow-Lin (Chow \& Lin, 1971) methodology is utilised for interpolation of quarterly data to monthly series with its advantageous implementation using Kalman filter in interpolation procedure through EViews software. All the financial, property and macroeconomic data are obtained from the CEIC Database.

\subsection{Markov-switching Bayesian vector autoregression model}

The Markov-switching framework implemented in this paper follows the Bayesian econometric tools developed by Sims et al. (2008). The Markov-switching Bayesian vector autoregression (MSBVAR) model contains several advantages for estimation, including assessment on the presence of nonlinearities, differentiation between variance switching and coefficient 
switching and investigation on the feedback and amplification effects between the real and financial sectors. Coefficient switching would indicate either a change in agents' behaviours during high financial vulnerability or a substantially dissimilar environment, whereas switching in variance indicates that the occurrence of the financial crises is by happenstance.

Financial vulnerability can be considered a tail event where two regimes are assumed a priori, particularly a low-vulnerability regime and high-vulnerability regime. The model is set up with four endogenous variables, comprising the financial vulnerability indicator, the inflation rate, GDP growth and the 1-month national interbank offered rate. Following Sims et al. (2008), the MSBVAR model is set up as follows:

$$
y_{t}^{\prime} A_{0}\left(s_{t}\right)=\sum_{j=1}^{l} y_{t-l}^{\prime} A_{j}\left(s_{t}\right)+z_{t}^{\prime} C\left(s_{t}\right)+\varepsilon_{t}^{\prime} \theta^{-1}\left(s_{t}\right), t=1,2, \ldots T a,
$$

where $y_{t}$ is an $n \times 1$ vector of endogenous variables; $s_{t}$ are unobservable (latent) state variables at time $t$. $l$ is the vector autoregression's (VAR's) lag length while $\varepsilon_{t}$ is the $n \times 1$ vector of random shocks. $z_{t}$ is a matrix of exogenous variables, which are set to a column vector of constant $1_{\mathrm{n}}$ (e.g., one intercept per equation). $A_{0}\left(s_{t}\right)$ is an $n \times n$ matrix of parameters describing contemporaneous relationships between the elements of $y_{t}, C\left(s_{t}\right)$ is a $1 \times n$ vector of parameters of the exogenous variables, $A_{j}\left(s_{t}\right)$ is an $n \times n$ matrix of parameters of the endogenous variables and sample size is denoted by $T$. The diagonal $n \times n$ matrix $\theta^{-1}\left(s_{t}\right)$ comprises the standard deviations of $\varepsilon_{t}$ where the structural shocks are epitomized through $\varepsilon_{t}^{\prime} \theta^{-1}\left(s_{t}\right)$. The values of $s_{t}$ are elements of $\left\{1,2, \ldots h^{m}\right\}$ and change according to a first-order Markov process with the following state probabilities:

$$
\operatorname{Pr}\left(s_{t}^{m}=i \mid s_{t-1}^{m}=k\right)=p_{i k}^{m}, i, k=1,2, \ldots h^{m} .
$$

Let us designate $Y_{t}=\left\{y_{0}, y_{1} \ldots y_{t}\right\}$ as the vector $y$ stacked in the time dimension. We assume that $\varepsilon_{t}$ is conditionally standard normal:

$$
p\left(\varepsilon_{t} \mid Y_{t-1}, S_{t}, A_{j}\right) \sim N\left(0_{n \times 1}, I_{n}\right) .
$$

The variance-covariance matrix $\Sigma\left(s_{t}^{m}\right)$ of the correlated reduced-form regression errors can be recovered as follows:

$$
\Sigma\left(s_{t}^{m}\right)=\left(A_{0}\left(s_{t}^{c}\right) \theta^{2}\left(s_{t}^{v}\right) A_{0}^{\prime}\left(s_{t}^{c}\right)\right)^{-1} .
$$

Since the matrix $A_{0}$ varies across coefficient regimes, $s_{t}^{c}$, the number of regimes of the correlated shocks is obtained as a multiple of the number of variance regimes of the structural shocks $s_{t}^{v}$ since the coefficients and variances are presumed to switch stochastically and independently.

The estimation of the model is initiated with the block-wise optimization algorithm for searching of posterior mode, particularly efficient for systems with large dimensions. The algorithm includes parameters divided into blocks and the initial parameter estimates undergo a hill-climbing quasi-Newton optimization routine. Priors are set for the VAR parameters and the state transition matrix. For the VAR parameters, the overall tightness of 0.56 is set for matrices A and F. For relative tightness of matrix F and the constant term, it is set at 0.17 and 0.1 , respectively, as suggested and implemented by Sims et al. (2008) for monthly data. 
The relative tightness of matrix $\mathrm{F}$ is based on its standard deviation of the prior around the $\mathrm{AR}(1)$ parameters while the tightness of the constant term is based on the standard deviation around the intercept. For the state transition matrix, the Dirichlet prior is used, setting at 5.6. An efficient prior for the problem under study is those produced with less variance switching than coefficient switching.

The MSBVAR model is set up with four endogenous variables. Let $y_{t}=\left[\begin{array}{llll}F V I & G & P\end{array}\right]$ ' where FVI represents the financial vulnerability indicator; $G$ is GDP growth; $P$ is CPI inflation; and $I$ denotes the national interbank offered rate. All variables are on a monthly basis and expressed at annual rates, excluding quarterly GDP data series, spanning from 1998M01 to 2018M06. All the data for the MSBVAR model are compiled from the CEIC database.

\section{Results and discussion}

The indicator construction through DAFM is calculated on a basis of 12 series of data from a mixture of financial market, property market and macroeconomic variables. All the variables can be categorised into four different sub-groups with their respective factor loadings reported in parentheses: real sector, external sector, financial sector and capital account. Variables for the first sub-group include real GDP (0.85), consumer price index (0.45), foreign direct investment (0.58), real estate investment (0.82) and the Shanghai Stock Exchange Index (0.13). The second sub-group comprises exports (0.76), imports (0.73) and the real effective exchange rate $(-0.19)$. In addition, the monetary aggregate M2 (0.47), total loans (0.45) and credit-to-GDP ratio (-0.34) are categorised as the third sub-group while the fourth sub-group is measured by total reserve (0.78).

The evolution of the FVI is illustrated in Figure 1. Several major episodes of vulnerability in Chinese economic history can be identified when analysing the time trend of the indicator. Based on the period under study, the first significant increase of financial vulnerability occurred before the dotcom bubble burst in 2000. The subsequent increase in vulnerability was due to the severe acute respiratory syndrome (SARS) outbreak in 2003 followed by a global commodity price hike in $2004 / 2005$. As a major demand for commodities, the rapid economic growth of China was hit by high inflation due to an upsurge in commodity prices. Neither the SARS outbreak nor the global commodity price hike hit China badly due to its strong growth. A period of relatively low vulnerability thereafter was disrupted with the global financial crisis in 2008, triggered by the collapse of Lehman Brothers. The quick drop in financial vulnerability is trailed by a sharp rise in vulnerability associated with massive inflows of investment in real estate and infrastructure. Considered "hot money", the huge investment in real estate and credit expansion triggered the unsustainable property price hike in 2010, which led to fear regarding vulnerability to the asset price bubble. Cooling measures from the Chinese authorities slowed down the property price and credit growth but both still remained excessive. Though the global economic meltdown in 2014 was triggered by the low commodity demand in China, high domestic consumption and credit expansion fuelled a low-vulnerability environment in the country before leading to the upsurge in financial vulnerability in 2016 due to the imminent credit bubble. 


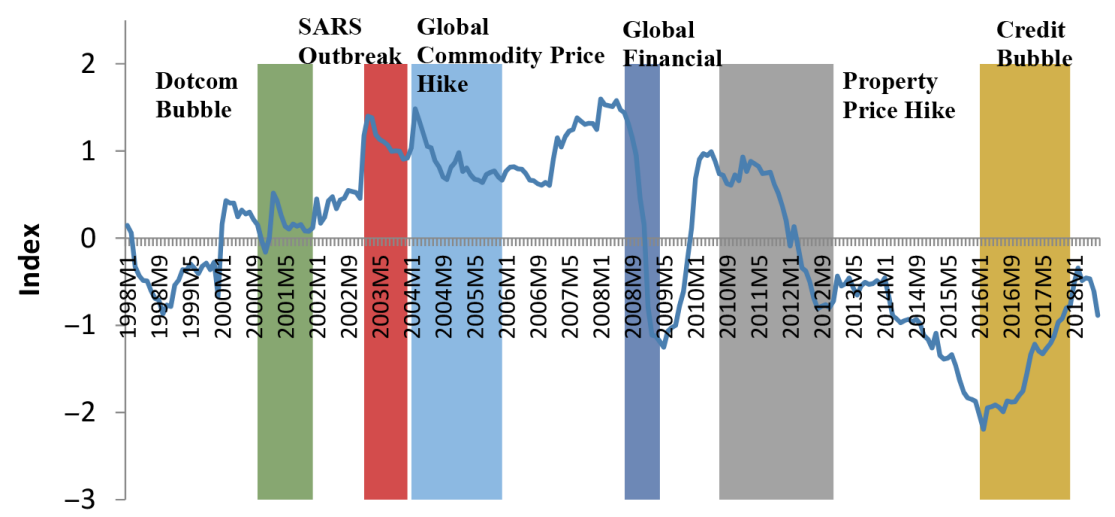

Figure 1. Financial vulnerability indicator for China. Shaded areas indicate vulnerability based on reports of various issues on China by the

International Monetary Fund, Asian Development Bank and World Bank

The decomposition of the FVI into four sub-groups enables tracking the source of financial vulnerability in different episodes, as depicted in Figure 2. Primarily, financial vulnerability in China was driven by real and external sector variables due to the country's high dependence on exports and investment, particularly with the dotcom bubble burst, the SARS outbreak, the global commodity price hike, the global financial crisis and the property price hike. In contrast, massive investment contributed appreciably to the low-vulnerability environment after the Asian financial crisis and the global financial crisis and during the global economic meltdown.

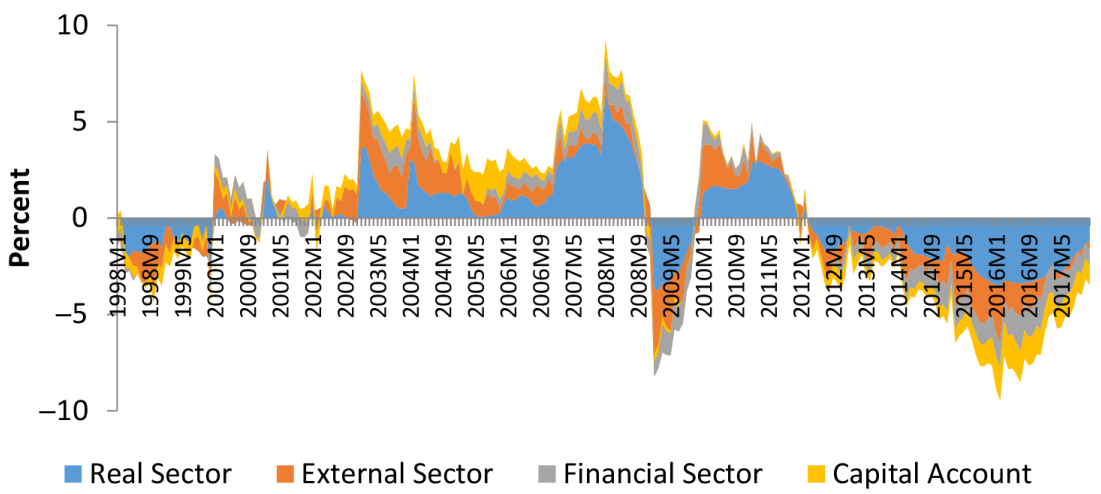

Figure 2. Contribution of indicator sub-groups

Table 1. Forecast evaluation results

\begin{tabular}{|l|c|c|c|c|c|c|}
\hline $\begin{array}{c}\text { Forecast } \\
\text { Evaluation }\end{array}$ & RMSE & MAE & MAPE & SMAPE & Theil U1 & Theil U2 \\
\hline FVI & 5.28 & 4.20 & 132.61 & 162.80 & 0.87 & 2.63 \\
\hline Credit Gap & 11.82 & 9.67 & 902.38 & 131.40 & 0.66 & 27.19 \\
\hline
\end{tabular}


For the forecast evaluation on the constructed indicator of FVI summarised in Table 1 , the indicator is evaluated against credit gap data of China published by the Bank for International Settlements. From the empirical outcomes, the constructed FVI contains lower values in terms of root mean square error, mean absolute error, mean absolute percentage error and Theil U2 while the credit gap data only portrays lower in values in term of symmetric mean absolute percentage error and Theil U1. The forecast evaluation results suggest the predictive power in the constructed indicator and serve as a robustness check for the indicator.

To obtain insights into the effects of financial vulnerability on economic activity, an MSBVAR model is implemented, focusing on the FVI, the 12-month growth rate of GDP, the inflation rate and the national interbank offered rate of China. Figure 3 depicts the Markovswitching model with the FVI, its conditional standard deviation on the second panel and the smoothed state probabilities over time on the third panel. Complementing with the outcomes of the conditional standard deviation and smoothed state probabilities, the model
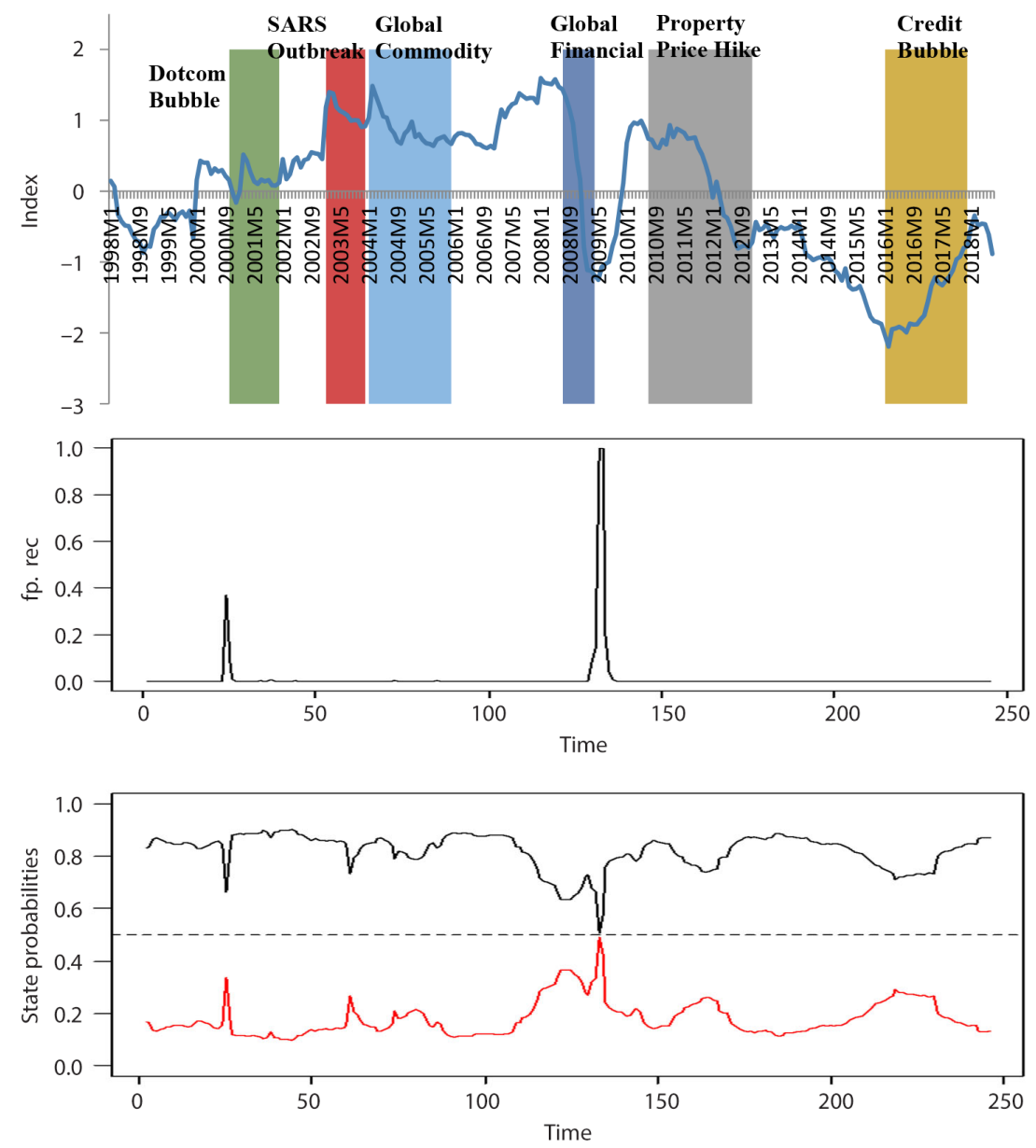

Figure 3. Markov switching model for the FVI 
indicates the very high probability that the Chinese economy was in a high-vulnerability regime (state 2) during the global financial crisis. Furthermore, a high probability of regime switching is also present during the dotcom bubble burst, the SARS outbreak, the property price hike and the credit bubble. For the transition probabilities, the estimated probability for $P_{11}$ is 71.84 percent while $P_{22}$ is 99.51 percent where Regime 1 and Regime 2 refer to low-vulnerability and high-vulnerability regime, respectively.

Figure 4 illustrates the functions of impulse response for the change in economic growth to a shock in the financial vulnerability indicator. The feedback of financial vulnerability varies substantially between the low-vulnerability regime and high-vulnerability regime. In the low-vulnerability regime, the shock in financial vulnerability has no substantial effects on the strong economic growth of the Chinese economy. On the other hand, a substantial change in economic growth in response to a financial vulnerability shock occurs in a high-vulnerability regime, whereby the GDP growth is lowered and impacted extensively. This signifies a slowdown in economic activity during a period of high vulnerability. The empirical findings highlight the prominence of nonlinearities in a crisis situation.

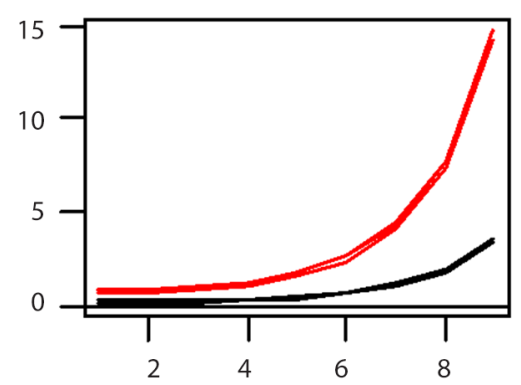

Figure 4. Impulses responses for change in GDP growth to shock in FVI. Black line denotes impulse response in low-vulnerability regime while red line denotes impulse response in high-vulnerability regime. The error band used is approximately one standard deviation as suggested by Sims and Zha (1999)

Though economic development in China has been blessed with a remarkable acceleration of double-digit growth since 1995, the empirical outcome suggests that financial vulnerability shock would eventually impact on the economic growth adversely. With the integration of financial markets and openness of Chinese economy, the potential vulnerabilities and unsustainable property prices would be menacing to its sustainable economic growth. Therefore, monitoring the potential financial vulnerabilities is vital to depress or even avert its spill-over effect to real economic activity in case of crisis occurrence.

\section{Conclusions}

Since the outbreak of the global financial crisis in 2008, monitoring the state of financial vulnerability has become a foremost concern for policy makers to provide a buffer for a macroprudential shock. In this paper, an FVI for China has been developed for application as a barometer for the state of financial vulnerability. Through the dynamic approximate factor 
model, the indicator is constructed using 12 variables from the financial market, property market and macroeconomic data from 1998 to 2018. One advantage of the methodology implemented, which permits an arbitrary pattern of missing data, is beneficial for construction of the indicator in real time.

Evaluation of the effects of financial vulnerability on economic activity is achieved through impulse response functions from MSBVAR modelling. The feedback for financial vulnerability varies substantially between regimes. In the low-vulnerability regime, the shock in financial vulnerability has no significant effects on economic growth. On the other hand, a significant change in economic growth in response to a financial vulnerability shock occurs in a high-vulnerability regime, whereby the change in GDP growth is negative extensively. This signifies a slowdown in economic activity during a period of high vulnerability. The empirical results emphasise the prominence of nonlinearities when analysing financial vulnerability shocks.

In line with other papers such as van Roye (2014), the main findings of this paper suggest that high financial vulnerability has a significant effect on output in China. Though the economy of China does not experience negative economic growth during the period under study, an economic slowdown still occurs as compared to double-digit growth during periods of low financial vulnerability. The findings also highlight the difference in the nature of the Chinese economy as an emerging market compared to other countries. Therefore, macroprudential authorities should consider the use of the constructed FVI and MSBVAR modelling as an early warning mechanism in monitoring the state of financial vulnerability so as to mitigate macroprudential risks which are hazardous to the economic sustainability in China.

Although the application of early warning mechanisms is useful and effective in many ways, there are still underlying limitations towards the developments of such mechanisms. For instance, not all issues have been taken into consideration in the development process due to data or information unavailability, such as the occurrence of natural disasters. With that, employment of various advanced methodologies, including wavelet and neural network application, would be necessary in the future to look into the issues from different angles while refining the effectiveness of such mechanisms.

\section{Funding}

This work was supported by Universiti Malaysia Sarawak (UNIMAS) under Fundamental Research Grant Scheme [F01/FRGS/1493/2016].

\section{Author contributions}

Tai-Hock Kuek, Chin-Hong Puah and M. Affendy Arip conceived the study and were responsible for the design and development of the data analysis. Tai-Hock Kuek was responsible for data collection and analysis. Tai-Hock Kuek and Chin-Hong Puah were responsible for data interpretation. Tai-Hock Kuek wrote the first draft of the article. Chin-Hong Puah, M. Affendy Arip and Muzafar Shah Habibullah were responsible in finalizing the article. 


\section{Disclosure statement}

The authors do not have any competing financial, professional, or personal interests from other parties.

\section{References}

Aboura, S., \& van Roye, B. (2017). Financial stress and economic dynamics: The case of France. International Economics, 149, 57-73. https://doi.org/10.1016/j.inteco.2016.11.001

Arip, M. A., Kuek, T. H., \& Puah, C. H. (2019). Forecasting financial vulnerability in Malaysia: A nonparametric indicator approach. Asian Journal of Business Research, 9(2), 113-120. https://doi.org/10.1407/ajbr.190063

Banbura, M., \& Modugno, M. (2014). Maximum likelihood estimation of factor models on datasets with arbitrary pattern of missing data. Journal of Applied Econometrics, 29(1), 133-160. https://doi.org/10.1002/jae.2306

Bruggemann, A., \& Linne, T. (2002). Are the central and Eastern European transition countries still vulnerable to a financial crisis? Results from the signals approach. (IWH Discussion Papers No. 157). Halle Institute for Economic Research, Saale, Germany. https://doi.org/10.2139/ssrn.1015699

Bussiere, M., \& Fratzscher, M. (2006). Towards a new early warning system of financial crises. Journal of International Money and Finance, 25, 953-973. https://doi.org/10.1016/j.jimonfin.2006.07.007

Cardarelli, R., Elekdag, S., \& Lall, S. (2011). Financial stress and economic contractions. Journal of Financial Stability, 7, 78-97. https://doi.org/10.1016/j.jfs.2010.01.005

Cecchetti, S. G., Mohanty, M. S., \& Zampolli, F. (2011). The real effects of debt (BIS Working Paper No. 352). Bank for International Settlements, Basel, Switzerland.

Cevik, E. I., Dibooglu, S., \& Kenc, T. (2013a). Measuring financial stress in Turkey. Journal of Policy Modeling, 35, 370-383. https://doi.org/10.1016/j.jpolmod.2012.06.003

Cevik, E. I., Dibooglu, S., \& Kenc, T. (2016). Financial stress and economic activity in some emerging Asian economies. Research in International Business and Finance, 36, 127-139. https://doi.org/10.1016/j.ribaf.2015.09.017

Cevik, E. I., Dibooglu, S., \& Kutan, A. M. (2013b). Measuring financial stress in transition economies. Journal of Financial Stability, 9, 597-611. https://doi.org/10.1016/j.jfs.2012.10.001

Chow, G., \& Lin, A. (1971). Best linear unbiased interpolation, distribution, and extrapolation of time series by related series. The Review of Economics and Statistics, 53, 372-375. https://doi.org/10.2307/1928739

Claessens, S., \& Kose, M. A. (2013). Financial crises: explanations, types, and implications. (IMF Working Paper Series No. 28). International Monetary Fund, Washington D.C., United States. https://doi.org/10.5089/9781475561005.001

Dempster, A. P., Laird, N. M., \& Rubin, D. B. (1977). Maximum likelihood from incomplete data via the EM algorithm. Journal of the Royal Statistical Society: Series B (Methodological), 39(1), 1-22. https://doi.org/10.1111/j.2517-6161.1977.tb01600.x

Ferrer, R., Jammazi, R., Bolos, V. J., \& Benitez, R. (2018). Interactions between financial stress and economic activity for the U.S.: A time- and frequency-varying analysis using wavelets. Physica A: Statistical Mechanics and its Applications, 492, 446-462. https://doi.org/10.1016/j.physa.2017.10.044

Illing, M., \& Liu, Y. (2006). Measuring financial stress in a developed country: An application to Canada. Journal of Financial Stability, 2, 243-265. https://doi.org/10.1016/j.jfs.2006.06.002 
International Monetary Fund. (2010). People's Republic of China: 2010 Article IV consultation. (IMF Country Report No. 10/238). Washington D.C., United States. https://doi.org/10.5089/9781455205868.002

International Monetary Fund. (2016). The People's Republic of China: Selected issues. (IMF Country Report No. 16/271). Washington D.C., United States. https://doi.org/10.5089/9781475524383.002

International Monetary Fund. (2018). People's Republic of China: 2018 Article IV consultation. (IMF Country Report No. 18/240). Washington D.C., United States. https://doi.org/10.5089/9781484338032.002

Ishrakieh, L. M., Dagher, L., \& Hariri, S. E. (2020). A financial stress index for a highly dollarized developing country: The case of Lebanon. Central Bank Review, 20(2), 43-52. https://doi.org/10.1016/j.cbrev.2020.02.004

Kaminsky, G. L., \& Reinhart, C. M. (1999). The twin crises: the causes of banking and balance-ofpayments problems. The American Economic Review, 89(3), 473-500.

https://doi.org/10.1257/aer.89.3.473

Kaminsky, G., \& Reinhart, C. M. (1996). The twin crises: The causes of banking and balance-of-payments problems (International Finance Discussion Paper, No. 544). Board of Governors of the Federal Reserve System, Washington D.C., United States. https://doi.org/10.17016/IFDP.1996.544

Kuek, T. H., Puah, C. H., \& Arip, M. A. (2019). Predicting financial vulnerability in Malaysia: Evidence from the signals approach. Research in World Economy, 10(3), 89-98. https://doi.org/10.5430/rwe.v10n3p89

Li, F. C., \& Xiao, H. Y. (2016). Early warning system of financial stress events: a credit-regime-switching approach. (Working Paper No. 21). Bank of Canada, Ottawa, Canada.

Louzis, D. P., \& Vouldis, A. T. (2012). A methodology for constructing a financial systemic stress index: An application to Greece. Economic Modelling, 29, 1228-1241. https://doi.org/10.1016/j.econmod.2012.03.017

Mishkin, F. S. (1991). Anatomy of a financial crises. (NBER Working Paper Series, No. 3934). National Bureau of Economic Research, Massachusetts, United States.

Monin, P. J. (2019). The OFR financial stress index. Risks, 7(25), 1-21. https://doi.org/10.3390/risks7010025

Pasricha, G., Roberts, T., Christensen, I., \& Howell, B. (2013). Assessing financial system vulnerabilities: an early warning approach. Bank of Canada Review, (Autumn 2013), 10-19.

Puah, C. H., Kuek T. H., \& Arip, M. A. (2017). Assessing Thailand's financial vulnerability: An early warning approach. Business and Economic Horizons, 13(4), 496-505. https://doi.org/10.15208/beh.2017.34

Sahoo, J. (2020). Financial stress index, growth and price stability in India: Some recent evidence. Theoretical and Applied Economics, 1(622), 105-124. https://doi.org/10.1080/19186444.2020.1768789

Sims, C. A., Waggoner, D. F., \& Zha, T. (2008). Methods for inference in large multi-equation Markovswitching models. Journal of Econometrics, 146(2), 255-274. https://doi.org/10.2139/ssrn.962420

Sims, C. A., \& Zha, T. (1999). Error bands for impulse responses. Econometrica, 67(5), 1113-1156. https://doi.org/10.1111/1468-0262.00071

Stona, F., Morais, I. A. C., \& Triches, D. (2018). Economic dynamics during periods of financial stress: Evidences from Brazil. International Review of Economics \& Finance, 55, 130-144. https://doi.org/10.1016/j.iref.2018.02.006

Tanaka, K., Kinkyo, T., \& Hamori, S. (2018). Financial hazard map: Financial vulnerability predicted by a random forests classification model. Sustainability, 10(5), 1530. https://doi.org/10.3390/su10051530

Suidarma, I. M., Indrawati, Y., Diatmika, I. G. N. D., \& Anggaradana, I. N. (2017). Financial system vulnerability indicators in Indonesia. International Journal of Economics and Financial Issues, 7(5), 299-306. 
Thakor, A. (2015). Lending booms, smart bankers, and financial crises. American Economic Review: Papers and Proceedings 2015, 105(5), 305-309. https://doi.org/10.1257/aer.p20151090

Tng, B. H., \& Kwek, K. T. (2015). Financial stress, economic activity and monetary policy in the ASEAN-5 economies. Applied Economics, 47(48), 5169-5185. https://doi.org/10.1080/00036846.2015.1044646

van Roye, B. (2014). Financial stress and economic activity in Germany. Empirica, 41(1), 101-126. https://doi.org/10.1007/s10663-013-9224-0

Yu, Y. D. (2010). The impact of the Global Financial Crisis on the Chinese economy and China's policy responses. Third World Network, Penang, Malaysia. 